\title{
Factors associated with lipid goal attainment among acute coronary syndrome patients
}

\author{
This article was published in the following Dove Press journal: \\ Patient Preference and Adherence \\ 24 August 2016 \\ Number of times this article has been viewed
}

\author{
Siti-Zainora Mohd-Zulkefli \\ Marhanis-Salihah Omar \\ Adyani Md-Redzuan \\ Faculty of Pharmacy, Universiti \\ Kebangsaan Malaysia, \\ Kuala Lumpur, Malaysia
}

Background: The incidence of acute coronary syndrome (ACS), one of the most common cardiovascular diseases, is high. Lipid goal attainment is one of the important factors to reduce the risk of recurrent heart attack. Identification of factors influencing lipid goal attainment such as age, female, race, underlying comorbidities, intensity of lipid-lowering therapy, patients' knowledge, and patients' belief about medicine would be beneficial in achieving the lipid goal. This study is aimed to determine lipid profile attainment and prescribing pattern of lipid-lowering therapy as well as to identify factors influencing lipid profile attainment among ACS patients.

Patients and methods: This researcher-assisted cross-sectional survey was carried out at a cardiology clinic in a tertiary hospital from March to May 2015.

Results: A total of 101 ACS patients were involved in this study. The mean values for lowdensity lipoprotein cholesterol (LDL-C) and high-density lipoprotein cholesterol levels were 2.75 $(0.82) \mathrm{mmol} / \mathrm{L}$ and $1.14(0.27) \mathrm{mmol} / \mathrm{L}$, respectively, while the median value for triglyceride level was $2.75(0.82) \mathrm{mmol} / \mathrm{L}$. Only $15.8 \%$ of our participants achieved the targeted LDL-C. Simvastatin $20 \mathrm{mg}$ was the most common regimen prescribed. Predictors for better LDL-C attainment were younger age $(\beta=-0.228 ; P=0.032)$ and higher knowledge score $(\beta=-0.255 ; P=0.049)$, while predictors for high-density lipoprotein cholesterol attainment were male $(\beta=0.268$; $P=0.006)$, smoking $(\beta=-0.192 ; P=0.045)$, and higher knowledge score $(\beta=-0.195 ; P=0.039)$. Smoking $(\beta=-0.361 ; P<0.0001)$ was the only predictor for higher triglyceride level.

Conclusion: Younger age, female, lower knowledge score, and smoking status are good predictors for lipid attainment among ACS patients.

Keywords: influence, disease, drug use, patient

\section{Introduction}

Cardiovascular diseases recorded the highest death rate in 2012 with 17.5 million deaths. ${ }^{1}$ The World Health Organization reported that the burden of coronary heart disease is expected to increase from 47 million disability-adjusted life years globally in 1990 to 82 million disability-adjusted life years in 2020. In Malaysia, a total of 16,872 patients were admitted to the hospital due to acute coronary syndrome (ACS) from 2006 till 2010 with an estimated incidence of 141 per 100,000 population per year. ${ }^{2}$ Proper risk factor management for ACS will improve patient's survival and quality of life. ${ }^{3}$

Achieving the targeted goal of lipid measurement is one of the important factors in preventing recurrent ACS. Most guidelines targeted the low-density lipoprotein cholesterol (LDL-C) as a goal of treatment outcome. ${ }^{4}$ The atherosclerotic effect of LDL-C is known to be associated with the risk of ACS. ${ }^{5}$ Lowering LDL-C to as low as $1.8-1.9 \mathrm{mmol} / \mathrm{L}$ is associated with additional benefit in reducing recurrent cardiovascular events. ${ }^{3-6}$ High-density lipoprotein cholesterol (HDL-C) is also found
Correspondence: Marhanis-Salihah Omar Faculty of Pharmacy, Universiti

Kebangsaan Malaysia, Jalan

Raja Muda Abdul Aziz, 50300

Kuala Lumpur, Malaysia

Tel +60 392898055

Fax +6039289327I

Email marhanis@ukm.edu.my 
to act as an independent risk factor of ACS. For every $10 \mathrm{mg} / \mathrm{dL}$ reduction in on-treatment triglyceride (TG), the incidence of death, myocardial infarction, and recurrent ACS will be reduced by $1.4 \% .^{7}$ Low TG is independent of LDL-C level, which reduces the risk of coronary heart disease. Thus, controlling the levels of LDL-C, HDL-C, and TG is important in order to prevent a second episode of myocardial infarction.

Statin therapy could be classified into three groups (ie, high-intensity statin therapy, moderate-intensity statin therapy, and low-intensity statin therapy). ${ }^{8}$ High-risk group of patients should be treated with high-intensity statin therapy. Nevertheless, targeted level of lipid attainment among ACS patients was still unachievable. Factors such as age and sex, chronic diseases, lipid-lowering therapy, patients' knowledge on risk factor of cardiovascular disease, and patients' belief toward medication may influence lipid attainment. ${ }^{9,10}$ Older age, Asian, diabetes, and hypertension as comorbidities, types of lipid-lowering therapy, and general knowledge on risk factors were recognized as significant predictors for LDL-C attainment. Promoting effective cholesterol management among ACS patients could be attained by understanding patient's beliefs and health experience. ${ }^{11}$ Optimization of lipid-lowering therapy and lifestyle modification is important in order to achieve the lipid goal attainment. ${ }^{12}$ This study is aimed to describe the lipid profile attainment and prescribing pattern of lipid-lowering therapy and to identify factors influencing lipid profile attainment among ACS patients.

\section{Patients and methods}

A cross-sectional survey was conducted among ACS patients who attended the Cardiology Clinic, Universiti Kebangsaan Malaysia Medical Centre, Kuala Lumpur, Malaysia, from March to May 2015. All patients aged $>18$ years and able to give informed consent, diagnosed with ACS regardless of their lipid profile, and on lipid-lowering therapy as secondary prevention medication were included. Those who were unable to complete the questionnaire, on lipid-lowering therapy for $<2$ months, or did not have the results of fasting serum lipid and Hbalc were excluded in this study. This study was approved by the UKM Research Ethics Committee (UKM 1.5.3.5/244/NF-005-15).

A validated questionnaire, the Heart Disease Fact Questionnaire (HDFQ), has been used in the study to measure the knowledge level of ACS risk factors. ${ }^{13}$ Patients who had higher total score would indicate a better knowledge on risk factors of heart disease. Cronbach $\alpha$ was conducted to validate the Malay language tools during the pilot study.
The result for Cronbach $\alpha$ (Malay language tools) was 0.732 . In this study, patients' belief about medicine was tested using Belief about Medicine Questionnaire (BMQ)-specific questionnaire. ${ }^{14}$ There were two subscales that covered both specific necessity (necessity of medication) and specific concern (concern about the use of the medication). Higher scores represent stronger beliefs of necessity or concern about medication.

In this study, the results of lipid parameters (ie, total cholesterol, LDL-C, HDL-C, and TG) and HbA1c level were referred to the latest lipid profile obtained during the current follow-up upon recruitment and were compared with those suggested in the treatment guidelines., ${ }^{3,4,6,8}$ The list of current lipid-lowering therapy used by the participants was obtained through the hospital computer database system and the intensity of statin therapy was classified into high-, moderate-, and low-intensity statin. ${ }^{11}$

\section{Statistical analysis}

Descriptive statistic was used to analyze the sociodemographic data, pattern of lipid-lowering therapy, knowledge on risk factor score, belief about medicine score, and lipid profile parameters. Categorical data were presented as frequency and percentage, whereas numerical data were presented as mean and SD or median and interquartile range depending on data normality. Any association between LDL-C and HDL-C in ACS patient and factors affecting the treatment outcome (ie, age, sex, smoking status, comorbidities, HbA1c level, lipid-lowering therapy, and patient's knowledge and belief about medicines) were determined using Student's $t$-test and analysis of variance test. Mann-Whitney test and Kruskal-Wallis test were used to determine the association between factors affecting the treatment outcome and TG levels. Pearson correlation and Spearman correlation were used to determine the relationship between patient's age, knowledge score, BMQ score, and HbA1c level with lipid profile attainment.

The relative strength of various factors toward lipid profile attainment was further analyzed by forward and backward method using multivariate regression model. Lipid profiles (ie, LDL-C, HDL-C, and TG) were entered as the dependent variables, while factors such as sex, race, smoking status, comorbidities, number of lipid-lowering drugs, intensity of statin therapy, age, knowledge score, BMQ score, and HbA1c were entered as independent variables. Smoking status, race, and intensity of statin therapy were dummy-coded for the purpose of entering these factors as dichotomous variables. For example, smoking status was coded as 1, whereas 
nonsmoking and ex-smoking status were coded as 0 . All statistical tests were two-tailed, and $P<0.05$ was denoted as statistical significance.

\section{Results}

A total of 101 study-eligible patients were recruited in this study upon their informed consent. More than $50 \%$ of participants aged $>65$ years, and men were found to be twice more common to develop ACS compared with women (Table 1). More than $50 \%$ of the participants had underlying hypertension and dyslipidemia, while other underlying diseases observed in this study were hypothyroidism, chronic obstructive airway disease, and malignancy. The mean of LDL-C level obtained from this study was found to be higher than the targeted LDL-C suggested by treatment guidelines (Table 2). There were six participants (5.9\%) and 30 participants $(29.7 \%$ ) who had TG level $>2.26 \mathrm{mmol} / \mathrm{L}$ and $1.69 \mathrm{mmol} / \mathrm{L}$, respectively. However, these patients failed to achieve the targeted non-HDL-C level (ie, $<2.59 \mathrm{mmol} / \mathrm{L}$ ), which was recommended by the treatment guidelines.

Table I Sociodemographic and baseline characteristics of study population $(n=101)$

\begin{tabular}{|c|c|}
\hline Characteristics & n (\%) \\
\hline Age, years mean (SD) & 65.51 (8.77) \\
\hline \multicolumn{2}{|l|}{ Sex } \\
\hline Male & $70(69.3)$ \\
\hline Female & $31(30.7)$ \\
\hline \multicolumn{2}{|l|}{ Race } \\
\hline Malay & $51(50.5)$ \\
\hline Chinese & $43(42.6)$ \\
\hline Indian & $6(5.9)$ \\
\hline Others & I (I.0) \\
\hline \multicolumn{2}{|l|}{ Marital status } \\
\hline Married & 100 (99.0) \\
\hline Single & I (I.0) \\
\hline \multicolumn{2}{|l|}{ Smoking status } \\
\hline Nonsmoker & $5 I(50.5)$ \\
\hline Ex-smoker & $4 I(40.6)$ \\
\hline Smoker & $9(8.9)$ \\
\hline \multicolumn{2}{|l|}{ Educational level } \\
\hline Secondary school & $38(37.6)$ \\
\hline Primary school & $31(30.7)$ \\
\hline College & $21(20.8)$ \\
\hline University & $9(8.9)$ \\
\hline None & $2(2.0)$ \\
\hline \multicolumn{2}{|l|}{ Premorbid } \\
\hline Hypertension & $86(85.1)$ \\
\hline Dyslipidemia & $73(72.3)$ \\
\hline Diabetes mellitus & $47(46.5)$ \\
\hline Renal failure & $13(12.9)$ \\
\hline Others & $6(5.9)^{\mathrm{a}}$ \\
\hline
\end{tabular}

Note: ${ }^{a}$ Chronic obstructive airway disease $(n=2)$; hypothyroidism $(n=2)$; and malignancy $(n=2)$

Abbreviation: SD, standard deviation.
Table 2 Lipid profile distribution of study population

\begin{tabular}{lll}
\hline $\begin{array}{l}\text { Laboratory } \\
\text { parameters }\end{array}$ & $\begin{array}{l}\text { Mean (SD) } \\
(\mathbf{m m o l} / \mathbf{L})\end{array}$ & $\begin{array}{l}\text { Median (IQR) } \\
\mathbf{( m m o l} / \mathbf{L})\end{array}$ \\
\hline Total cholesterol & $4.58(\mathrm{I} .04)$ & \\
LDL-C & $2.75(0.82)$ & \\
HDL-C & $1.14(0.27)$ & $3.36(1.10)$ \\
Non HDL-C & & $1.44(0.65)$ \\
TG & & \\
\hline
\end{tabular}

Abbreviations: IQR, interquartile range; LDL-C, low-density lipoprotein cholesterol; HDL-C, high-density lipoprotein cholesterol; TG, triglyceride.

More than $75 \%$ of the participants received moderateintensity statin and majority of them were treated with single lipid-lowering therapy agent (Table 3).

Table 4 shows the factors that had significant differences in mean of LDL-C, HDL-C, and median TG levels and significant correlation between continuous variables and lipid profiles. Participants with renal failure as a comorbidity were found to have significant lower mean LDL-C level ( $t=-2.685 ; P=0.013)$. In addition, there was a significant inverse but weak correlation $(|r|=0.227 ; P=0.023)$ between age and LDL-C level. Furthermore, females had higher mean HDL-C level compared with males $(t=-2.786 ; P=0.008)$. There was also a significant difference in mean HDL-C level between smoking status $(F=3.928 ; P=0.023)$. Further post hoc analysis found that nonsmokers had higher mean HDL-C level compared with smokers $(P=0.02)$. Additionally, there was a weak but significant inverse correlation between patients' knowledge and HDL-C level $(|r|=0.200$; $P=0.045)$. For TG level, smoking status was found to have significant association with TG level $\left(\chi^{2}=9.881 ; P=0.007\right)$. Further post hoc analysis found that the median of TG for ex-smokers was lower than smokers $(Z=-2.740 ; P=0.006)$ and nonsmokers $(Z=-1.996, P=0.046)$. In addition, the median value of TG for nonsmokers was lower than that for smokers $(Z=-2.061 ; P=0.039)$. Moreover, the HbA1c level had significant positive but weak correlation with TG level $(|r|=0.200 ; P=0.044)$.

Table 3 Pattern of prescribing lipid-lowering therapy

\begin{tabular}{ll}
\hline Intensity of statin therapy & $\mathbf{N}(\%)$ \\
\hline High-intensity $^{\mathrm{a}}$ & $2 \mathrm{I}(20.8)$ \\
Moderate-intensity $^{\mathrm{b}}$ & $79(78.2)$ \\
Low-intensity $^{\mathrm{c}}$ & $\mathrm{I}(1.0)$ \\
Single therapy & $94(93.1)$ \\
Combined therapy $^{\mathrm{d}}$ & $7(6.9)$ \\
\hline
\end{tabular}

Notes: aAtorvastatin $40 \mathrm{mg}$ daily $(n=12)$, atorvastatin $80 \mathrm{mg}$ daily $(\mathrm{n}=2)$, and rosuvastatin $20 \mathrm{mg}$ daily $(\mathrm{n}=7)$. bSimvastatin $20 \mathrm{mg}$ daily $(\mathrm{n}=29)$, simvastatin $40 \mathrm{mg}$ daily $(n=27)$, and lovastatin $40 \mathrm{mg}$ daily $(n=23)$. 'Lovastatin $20 \mathrm{mg}$ daily $(n=I)$. dFenofibrate $160 \mathrm{mg}$ daily $(\mathrm{n}=6)$ and ezetimibe $10 \mathrm{mg}$ daily $(\mathrm{n}=\mathrm{l})$. 
Table 4 Association between factors and lipid profile attainment

\begin{tabular}{|c|c|c|c|c|}
\hline Variables & Mean (SD) & Statistic & $P$-value & Pearson correlation $r ; P$-value \\
\hline \multicolumn{5}{|l|}{ Comorbidities } \\
\hline Renal failure & $2.356(0.507)$ & $t=-2.685$ & $0.013^{*}$ & \\
\hline Nonrenal failure & $2.804(0.844)$ & & & \\
\hline Age & & & & $-0.227 ; 0.023 *$ \\
\hline \multicolumn{5}{|l|}{ Sex } \\
\hline Male & I.09I (0.204) & $t=-2.786$ & $0.008^{*}$ & \\
\hline Female & $1.254(0.296)$ & & & \\
\hline \multicolumn{5}{|l|}{ Smoking status } \\
\hline Smokers & $0.847(0.140)$ & $F=3.928$ & $0.023^{*++}$ & \\
\hline Ex-smokers & I.I $28(0.218)$ & & & \\
\hline Nonsmokers & I.186 (0.267) & & & \\
\hline \multirow[t]{2}{*}{ Patients' knowledge on CVD risk factors } & & & & $-0.200 ; 0.045^{*}$ \\
\hline & Median (IQR) & Statistic & P-value & Spearman correlation $r_{s} ; P$-value \\
\hline \multicolumn{5}{|r|}{ 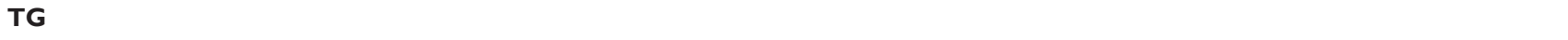 } \\
\hline \multicolumn{5}{|l|}{ Smoking status } \\
\hline Smokers & $\mathrm{I} .790(1.020)$ & $\chi^{2}=9.881$ & $0.007^{*, \#}$ & \\
\hline Ex-smokers & $1.260(0.480)$ & & & \\
\hline Nonsmokers & $1.490(0.580)$ & & & \\
\hline $\mathrm{HbAlc}$ & & & & $0.200 ; 0.044 *$ \\
\hline
\end{tabular}

The variables in a linear regression model explained $8.1 \%, 14.2 \%$, and $12.1 \%$ of variance in reported LDL-C, HDL-C, and TG levels, respectively. Table 5 shows the percentage of variance explained for individual variables of LDL-C, HDL-C, and TG levels. Participant's knowledge score became a stronger predictor for LDL-C level compared with age. Younger age and lower knowledge score were found to be significant predictors of higher LDL-C level. Female sex was the strongest predictor for HDL-C level, since women were foreseen to have higher HDL-C levels. Remarkably, participants with lower knowledge score were predicted to have higher HDL-C level, while smokers were predicted to have lower HDL-C and higher TG levels.

\section{Discussion}

Among the subtypes of lipid component, elevated level of LDL-C was the most established factor responsible for higher risk of ACS. In our study, there was low percentage of patients who achieved the recommended LDL-C goal, which was consistent with that reported elsewhere. ${ }^{15-17}$ Low mean HDL-C level seen in our participants could be attributed to the lack of attention on HDL-C level being paid by physicians during the assessment and interpretation of laboratory results. Although none of the recommended guidelines set any HDL-C goal attainment, low HDL-C levels were associated with increased cardiovascular events even if the patients were prescribed statin therapy. ${ }^{18}$

Table 5 Multivariate regression model for lipid profile attainment

\begin{tabular}{|c|c|c|c|c|c|c|c|c|c|}
\hline \multirow[t]{2}{*}{ Variables } & \multicolumn{3}{|l|}{ LDL-C } & \multicolumn{3}{|l|}{ HDL-C } & \multicolumn{3}{|c|}{ Triglyceride } \\
\hline & $\beta^{a}$ & $P$-value & $\begin{array}{l}\text { Adjusted } R^{2} \\
\text { (\% variance } \\
\text { explained) }\end{array}$ & $\beta^{\mathbf{b}}$ & $P$-value & $\begin{array}{l}\text { Adjusted } R^{2} \\
\text { (\% variance } \\
\text { explained) }\end{array}$ & $\beta^{c}$ & $P$-value & $\begin{array}{l}\text { Adjusted } R^{2} \\
\text { (\% variance } \\
\text { explained) }\end{array}$ \\
\hline Age & -0.228 & $0.006 *$ & $0.032(3.2 \%)$ & & NR & & & NR & \\
\hline Patient's & -0.255 & $0.014 *$ & $0.049(4.9 \%)$ & -0.195 & $0.039 *$ & $0.031(3.1 \%)$ & & NR & \\
\hline \multicolumn{10}{|l|}{ knowledge score } \\
\hline Female & & NR & & 0.268 & $0.006 *$ & $0.084(8.4 \%)$ & & NR & \\
\hline Smokers-status & & NR & & -0.192 & $0.045^{*}$ & $0.027(2.7 \%)$ & 0.361 & $<0.000 I^{*}$ & $0.121(12.1 \%)$ \\
\hline
\end{tabular}

Notes: Forward and backward logistic regression methods were applied. Constant: ${ }^{a} 5.717$, b ${ }^{\circ} .496$, and ${ }^{c} \mid .418$. NR, variables entered but not retained. $* P<0.05$ denoted statistical significant difference.

Abbreviations: LDL-C, low-density lipoprotein cholesterol; HDL-C, high-density lipoprotein cholesterol. 
Achieving higher level of HDL-C was important as the inverse relationship between HDL-C level and coronary risk still persists even in patients with low LDL-C. ${ }^{19}$ Furthermore, low HDL-C level had been associated with higher in-hospital death rate. ${ }^{20}$

The lack of awareness of the importance of controlling TG and non-HDL-C levels could be the reason why the targeted level of non-HDL has failed to be achieved in our participants. ${ }^{17,21}$ Although there was no specific TG goal attainment mentioned in the guidelines, the PROVE IT-TIMI 22 trial had reported that low on-treatment TG $(<1.69 \mathrm{mmol} / \mathrm{L})$ that was independent of the level of LDL-C would reduce the risk of coronary heart disease. ${ }^{7}$ Combination of low LDL-C $(<1.8 \mathrm{mmol} / \mathrm{L})$ and low TG $(<1.69 \mathrm{mmol} / \mathrm{L})$ was also associated with the lowest event rates compared with higher LDL-C, higher TG, or both.

In our study, simvastatin $20 \mathrm{mg}$ was prescribed the most to the ACS patients in accordance with the local institutional practice, which favored the use of simvastatin and lovastatin. The participant's awareness on the three different intensity categories of statin might be overlooked by the physician as it was only mentioned in recent guidelines or different policies of prescribing medication in local practice, insurance benefit, potential difference in knowledge, and awareness among physician and patients regarding lipid management. Comprehensive information at initial prescription, initiation of statins during hospitalization, dose adjustment during follow-up, comedication as possible seem to increase the level of awareness of the benefits of long-term statin treatment. ${ }^{22}$ The lack of awareness on the controlling TG level and risk of developing rhabdomyolysis could also lead to the low prescribing pattern of combination statin-fibrate therapy. The risk of rhabdomyolysis should be balanced with the benefit of achieving lipid goal and suitable strategies could be outlined prior to the use of combination statin therapy especially in patient with high risk of developing rhabdomyolysis. ${ }^{23,24}$ On the other hand, nonrenal failure and younger age were associated with higher LDL-C level in our study, in contrast to what had been reported elsewhere. ${ }^{25,26}$ The differences in daily lifestyle and eating habits, aggressive treatment for renal failure due to higher risk of elevated LDL-C, and atherosclerosis could be the answer for the observed differences. The young patients tend to get overwhelmed with their daily working routine, compromising their time for healthy lifestyle, such as having regular physical activity and eating healthy balanced diet. Older patients, conversely, were more concerned and focused to have healthier lifestyle following myocardial infarction.
High HDL-C occurred in $\sim 20 \%$ of women with coronary heart disease. ${ }^{25}$ ACS was likely to involve postmenopause women, which might encourage the physician to achieve the better HDL-C level among women. ${ }^{27}$ Other factors that might be associated with high level of HDL-C in women were lower waist circumference, lower body mass index, and metabolic syndrome. ${ }^{8}$ Lower level of HDL-C among smokers might be due to sedentary lifestyle and lack of exercise among smokers leading to low level of HDL-C. Interestingly, our study showed that higher knowledge score was associated with lower HDL-C level. This might be due to less awareness on the importance of increasing HDL-C among the participants. There was lack of study looking at the association between patient's knowledge and HDL-C level specifically; nevertheless, education program is warranted to increase patients' knowledge to achieve better lipid goal attainment. ${ }^{9}$

The basis of TG level may be helpful for the risk stratification and management in patients with ACS. ${ }^{21}$ The risk of heart disease increases with the number of cigarettes smoked per day. Cigarette consumption is an important risk factor for ACS and higher TG level had been observed previously in smokers. ${ }^{28}$ In our study, former smokers were found to have low TG levels compared with the current smokers and nonsmokers, which might be due to the influence of smoking toward the metabolism of TG. The sedentary lifestyle and lack of exercise among smokers might also contribute to high level of TG. Furthermore, smokers were predicted to have lower HDL and higher TG, hence emphasizing that the importance of smoking cessation is an important element in managing ACS patients. Elevated TG level is the common dyslipidemic feature accompanying type 2 diabetes and prediabetic states. ${ }^{29}$ The HbA1c was found to be associated with TG levels in our participants, possibly due to the fact that patients with uncontrolled diabetes are likely to obtain higher TG level. Increase in hepatic LDL production and defective removal of chylomicrons and chylomicron remnants (ie, product of TG hydrolysis) could explain the reason of high TG in diabetes patients. ${ }^{7}$ Participants with low knowledge score might have higher LDL-C level; hence, they should be properly educated on cardiovascular diseases. Counseling on disease background, goal of therapy, and importance of compliance toward medication during cardiac rehabilitation program might help in improving their knowledge. ${ }^{30}$ Continuous education should be given to remind the patient the importance of attaining lipid goal.

In general, we reported that younger age, female, lower knowledge score, and nonsmokers or former smokers are 
good predictors for lipid attainment among ACS patients. Nevertheless, these findings should be interpreted cautiously due to several limitations of the study. First, for the HDFQ, patients might tend not to choose the choice of "do not know" as their option besides pretending that they know the answer. Second, for the BMQ survey, some might remain doubtful that this research might affect the treatment provided by the clinical team. Consequently, the agreement on the statements listed in BMQ tools might alter from their true belief about medicine. Third, it was assumed that the blood withdrawn and sent to the laboratory for lipid profile level was taken at fasting state. However, there was no information provided guaranteeing that the patient fasted prior to blood withdrawal. Furthermore, the number of questions in this survey was limited to obtain reasonable time for interview session, which subsequently could prevent any other potential predictors (eg, adherence level, dietary intake, and physical activity) of lipid profile attainment to be included in this survey.

\section{Conclusion}

Younger age, female, lower knowledge score, and smoking status are good predictors for lipid attainment among ACS patients. Our study on factors influencing lipid profile among ACS patients shows that there is significant room for improvement. Future studies are recommended to identify more potential predictors of lipid attainment to provide better lipid profile outcome.

\section{Disclosure}

The authors report no conflicts of interest in this work.

\section{References}

1. World Health Organisation (www.who.int) [webpage on the Internet]. NCD Mortality and Morbidity. World Health Organization. Available from: http://www.who.int/gho/ncd/mortality_morbidity/en/. Accessed December 2015.

2. Wan Azman WA, Sim KH. Annual Report of the Acute Coronary Syndrome (ACS) Registry 2009-2010. National Heart Association of Malaysia (NHAM) and the Ministry of Health Malaysia; 2011.

3. Smith SC, Benjamin EJ, Bonow RO, et al. AHA/ACCF secondary prevention and risk reduction therapy for patients with coronary and other atherosclerotic vascular disease: 2011 update: a guideline from the American Heart Association and American College of Cardiology Foundation endorsed by the World Heart Federation and the Preventive Cardiovascular Nurses Association. J Am Coll Cardiol. 2011; 58(23):2432-2446.

4. National Cholesterol Education Program (NCEP) Expert Panel on Detection, Evaluation, and Treatment of High Blood Cholesterol in Adults (Adult Treatment Panel III). Third Report of the National Cholesterol Education Program (NCEP) Expert Panel on Detection, Evaluation and treatment of high blood cholesterol in adults (adult treatment panel III) final report. Circulation. 2002;106(25):3143.
5. Perk J, De Backer G, Gohlke H, et al; European Association for Cardiovascular Prevention \& Rehabilitation (EACPR); ESC Committee for Practice Guidelines (CPG). European Guidelines on Cardiovascular Disease Prevention in Clinical Practice (version 2012): The Fifth Join Task Force of the European Society of Cardiology and Other Societies on Cardiovascular Disease Prevention in Clinical Practice. Atherosclerosis. 2012;223(1):1-68.

6. Academy of Medicine of Malaysia [webpage on the Internet]. Clinical Practice Guidelines on Management of Unstable Angina/Non ST Elevation Myocardial Infarction (UA/NSTEMI). Malaysia: Ministry of Health; 2011. Available from: www.acadmed.org.my. Accessed December 2015.

7. Miller M, Cannon CP, Murphy SA, et al. Impact of triglyceride levels beyond low-density lipoprotein cholesterol after acute coronary syndrome in the PROVE IT-TIMI 22 trial. J Am Coll Cardiol. 2008; 51(7):724-730.

8. Stone NJ, Robinson J, Lichtenstein AH, et al. 2013 AHA/ACCF Guideline on the treatment of blood cholesterol to reduce atherosclerotic risk in adults. J Am Coll Cardiol. 2014;63(25 Pt B):2889-2934.

9. Waters DD, Brontons C, Chiang C, et al; Lipid Treatment Assessment Project 2 Investigators. Lipid treatment assessment project 2: a multinational survey to evaluate the proportion of patients achieving low-density lipoprotein cholesterol goals. Circulation. 2009;120(1): 28-34.

10. Alm-Roijer C, Stagmo M, Udén G, Erhardt L. Better knowledge improves adherence to lifestyle changes and medication in patients with coronary heart disease. Eur J Cardiovasc Nurs. 2004;3(4): 321-330.

11. Ayanian JZ, Landon BE, Landrum MB, Grana JR, Mc Neil BJ. Use of cholesterol-lowering therapy and related beliefs among middle-aged adults after myocardial infarction. J Gen Intern Med. 2002;17(2): 95-102.

12. Martineau P, Gaw A, de Teresa E, et al; ACTFAST investigators. Effect of individualizing starting doses of a statin according to baseline LDLcholesterol levels on achieving cholesterol targets: the achieve cholesterol targets fast with atorvastatin startified titration (ACTFAST-1) study. Atherosclerosis. 2007;191(1):135-146.

13. Wagner J, Lacey K, Chyun D, Abbott G. Development of a questionnaire to measure heart disease risk knowledge in people with diabetes: the heart disease fact questionnaire. Patient Educ Couns. 2005;58(1): $82-87$.

14. Horne R, Weinman J, Hankins M. The beliefs about medicines questionnaire: the development and evaluation of a new method for assessing the cognitive representation of medication. Psychol Health. 1999;14(1):1-24.

15. Chin CW, Gao F, Le T, Tan RS. Lipid goal attainment and prescription behavior in Asian patients with acute coronary syndromes: experience from a tertiary hospital. Clin Med Insights Cardiol. 2013;7:51-57.

16. Chinwong D, Patumanond J, Chinwong S, et al. Statin therapy in patients with acute coronary syndrome: low-density lipoprotein cholesterol goal attainment and effect of statin potency. Ther Clin Risk Manag. 2015;11:127-136.

17. Manurung D. Lipid profiles of acute coronary syndrome patients hospitalized in ICCU of Cipto Mangunkusumo Hospital. Acta Med Indones J Intern Med. 2006;38(4):196-201.

18. Rosenson RS, Brewer HB, Rader DJ. Lipoproteins as biomarkers and therapeutic targets in the setting of acute coronary syndrome. Circ Res. 2014;114(12):1880-1889.

19. deGoma EM, Leeper NJ, Heidenreich PA. Clinical significance of high-density lipoprotein cholesterol in patients with low low-density lipoprotein cholesterol. J Am Coll Cardiol. 2008;51(1):49-55.

20. Ji MS, Jeong MH, Ahn YK, et al. Impact of low level of high-density lipoprotein-cholesterol sampled in overnight fasting state on the clinical outcomes in patients with acute myocardial infarction (difference between ST-segment and non-ST-segment-elevation myocardial infarction). J Cardiol. 2015;65(1):63-70. 
21. Islam MZ, Faruque M, Bari MA, et al. Correlation of triglyceride level with acute coronary syndrome. Mymensingh Med J. 2012;21(1): 44-48.

22. Yilmaz MB, Biyikogly SF, Guray Y, et al. Level of awareness of ontreatment patients about prescribed statins. Cardiovasc Drugs Ther. 2004; 18(5):399-404.

23. Hu D, Li J, Li X. China Cholesterol Education Program. Investigation of blood lipid levels and statin interventions in outpatients with coronary heart disease in China. Circ J. 2008;72(12):2040-2045.

24. Siraluks S, Sriratanasathavorn C, Rawdaree P, Kunjara-Na-Ayudhaya R, Thinkhamrop B, Sritara P. Lipid-lowering therapy using statins in patients with cardiovascular risk in clinical practice in Thailand. Heart Asia. 2011;3(1):99-103.

25. Igel-Korcagova A, Raab P, Brensing KA, et al. Cholesterol metabolism in patients with chronic renal failure on hemodialysis. J Nephrol. 2003;16(6):850-854.
26. Schaefer EJ, Lamon-Fava S, Cohn SD, et al. Effect of age, gender, and menopausal status on plasma low density lipoprotein cholesterol and apolipoprotein B levels in the Framingham Offspring study. J Lipid Res. 1994;35(5):779-792.

27. Batic-Mujanovic O, Zildzic M, Beqanlic A, Kusljugić Z. The effect of cigarette smoking on HDL-cholesterol level. Med Arh. 2006; 60(6 suppl 2):90-92.

28. Devaranavadgi B, Aski BS, Kashinath RT, Hundekari IA. Effect of cigarette on blood lipids- a study in Belgaum, Nothern Karnataka, India. Global J Med Res. 2012;12(6):57-71.

29. Tirosh A, Shai I, Bitzur R, et al. Changes in triglyceride levels changes in triglyceride levels over time and risk of type 2 diabetes in young men. Diabetes Care. 2008;31(10):2032-2037.

30. Mampuya WM. Cardiac rehabilitation past, present and future: an overview. Cardiovasc Diagn Ther. 2012;2(1):38-49.

\section{Publish your work in this journal}

Patient Preference and Adherence is an international, peer-reviewed, open access journal that focuses on the growing importance of patient preference and adherence throughout the therapeutic continuum. Patient satisfaction, acceptability, quality of life, compliance, persistence and their role in developing new therapeutic modalities and compounds to optimize clinical outcomes for existing disease states are major areas of interest for the journal. This journal has been accepted for indexing on PubMed Central. The manuscript management system is completely online and includes a very quick and fair peer-review system, which is all easy to use. Visit http://www. dovepress.com/testimonials.php to read real quotes from published authors.

Submit your manuscript here: http://www.dovepress.com/patient-preference-and-adherence-journal 